\title{
Nuclear Cryogenic Propulsion Stage (NCPS) Fuel Element Testing in the Nuclear Thermal Rocket Element Environmental Simulator (NTREES)
}

\author{
William J. Emrich, $\mathrm{Jr}^{1}$ \\ NASA Marshall Space Flight Center, Huntsville, Alabama, 35812
}

To support the on-going nuclear thermal propulsion effort, a state-of-the-art non nuclear experimental test setup has been constructed to evaluate the performance characteristics of candidate fuel element materials and geometries in representative environments. The facility to perform this testing is referred to as the Nuclear Thermal Rocket Element Environment Simulator (NTREES). Last year NTREES was successfully used to satisfy a testing milestone for the Nuclear Cryogenic Propulsion Stage (NCPS) project and met or exceeded all required objectives.

\section{Introduction}

$\mathrm{T}$ he NTREES facility is designed to perform realistic non-nuclear testing of nuclear thermal rocket (NTR) fuel

elements and fuel materials in representative environments and is licensed by the Nuclear Regulatory Commission to handle fuel elements containing depleted uranium. Although the NTREES facility cannot mimic the neutron and gamma environment of an operating NTR, it can simulate the thermal hydraulic environment within an NTR fuel element to provide critical information on material performance and compatibility ${ }^{1}$. To satisfy the Nuclear Cryogenic Propulsion Stage (NCPS) testing milestone, a graphite composite fuel element using a uranium simulant was received from the Oakridge National Lab and tested in the NTREES at various operating conditions. The nominal operating conditions required to satisfy the milestone consisted of running the fuel element for approximately five minutes (the operation time was not specifically defined) at a temperature of at least $2000 \mathrm{~K}$ with flowing hydrogen. This milestone test was successfully accomplished without incident.

\section{Testing Activities}

The test article received from Oakridge consisted of a fuel element composed of a graphite composite materal about 16 inches long containing 4 coolant channels. Prior analyses of the fuel element indicated that it should survive testing up to approximately $2000 \mathrm{~K}$. A photograph of the fuel element tested in NTREES is presented in Figure 1.

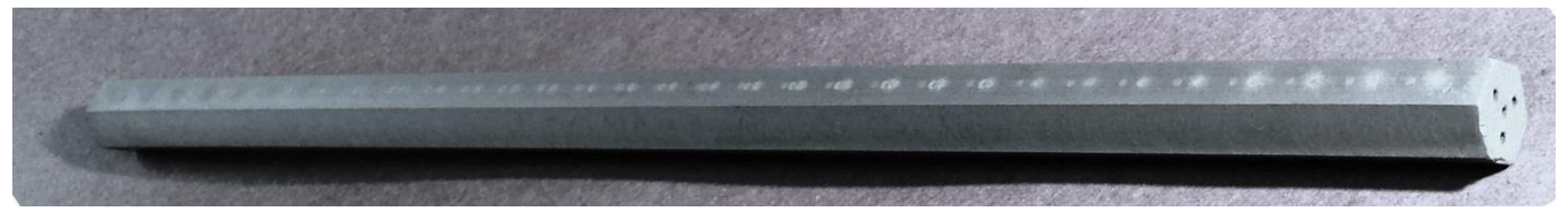

Figure 1 Oakridge Fuel Element Tested in NTREES to Meet the NCPS Milestone

\footnotetext{
${ }^{1}$ Senior Engineer, Propulsion System Department, Mail Stop ER24, AIAA Associate Fellow.
} 
The testing began by loading the fuel element into NTREES and subjecting it to an axial loading of approximately 35 pounds. The NTREES chamber was then closed and the atmosphere was inerted with nitrogen gas and pressurized to approximately $200 \mathrm{psig}$. A hydrogen flow through the fuel element was then established at approximately $1 \mathrm{gm} / \mathrm{sec}$. After the hydrogen flow was properly set, the induction heater was energized and power applied to the fuel element. The power and maximum temperature profiles which the fuel element encountered during the test are illustrated in Figure 2. A view of the fuel element at approximately $2000 \mathrm{~K}$ is presented in Figure 3. The desired $2000 \mathrm{~K}$ temperature in the fuel element was achieved at an induction power level of approximately $65 \mathrm{~kW}$ or at just over $5 \%$ of the power available from the $1.2 \mathrm{MW}$ induction heating unit.

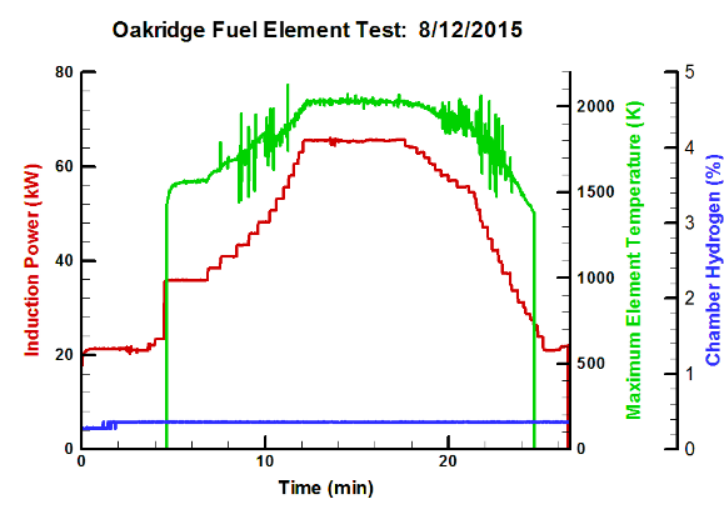

Figure 2 Nominal Test Conditions

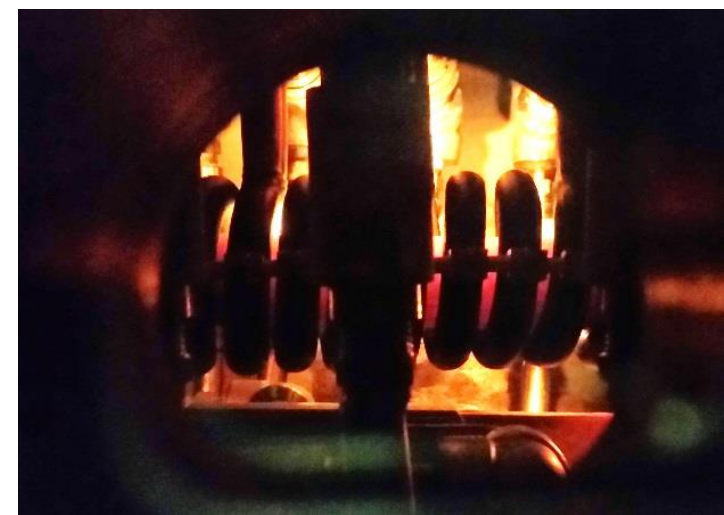

Figure 3 Fuel Element at Nominal Power

During the testing, the fuel element behaved as expected indicating that it likely survived the nominal testing conditions intact thus meeting all the predetermined project objectives. After the test concluded, the NTREES test chamber was depressurized and the fuel element allowed to cool to room temperature. The NTREES test chamber was then opened up and the fuel element removed. A visual inspection of the fuel element after the test confirmed that no damage had occurred to the fuel element thereby satisfying testing milestone required by the NCPS project. Figure 4 illustrates the condition of the fuel element after the test was completed. Note that the surface shows no obvious signs of damage.

Having met the project milestones, it was decided to reinsert the fuel element into NTREES and perform additional testing. This additional testing was designed to be much more severe than that which was performed during the first test and was intended to take the fuel element to the point of failure. As before, the fuel element was loaded into NTREES and subjected to an axial loading of approximately 35 pounds. The NTREES chamber was then closed and the chamber inerted with nitrogen gas and pressurized to approximately 250 psig. For this test the hydrogen flow rate within the fuel element was established at approximately $2 \mathrm{gm} / \mathrm{sec}$. The induction heater was energized once again and power applied to the fuel element. The power and maximum temperature profiles which the fuel element encountered during this test are illustrated in Figure 5. A view of the fuel element at approximately $2800 \mathrm{~K}$ is illustrated in Figure 6. Note especially the increase in brightness of the fuel element in

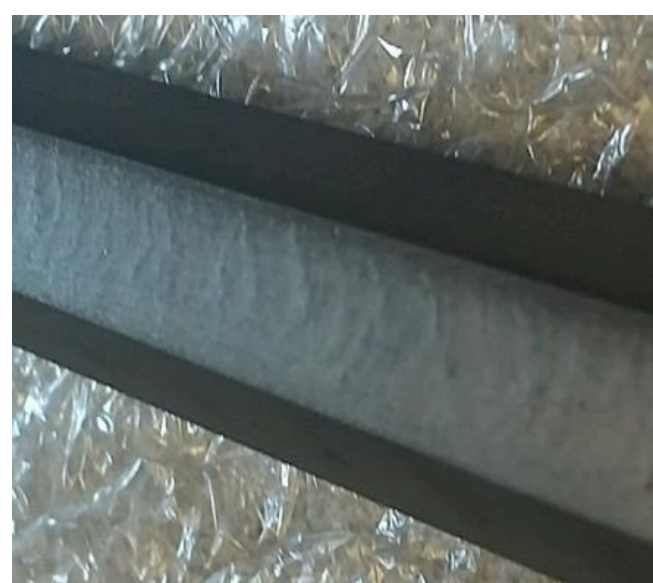

Figure 4 Testing Shows No Visible Damage

Figure 5 as compared to Figure 3 indicating the much higher fuel element temperatures achieved during this more aggressive testing sequence. 


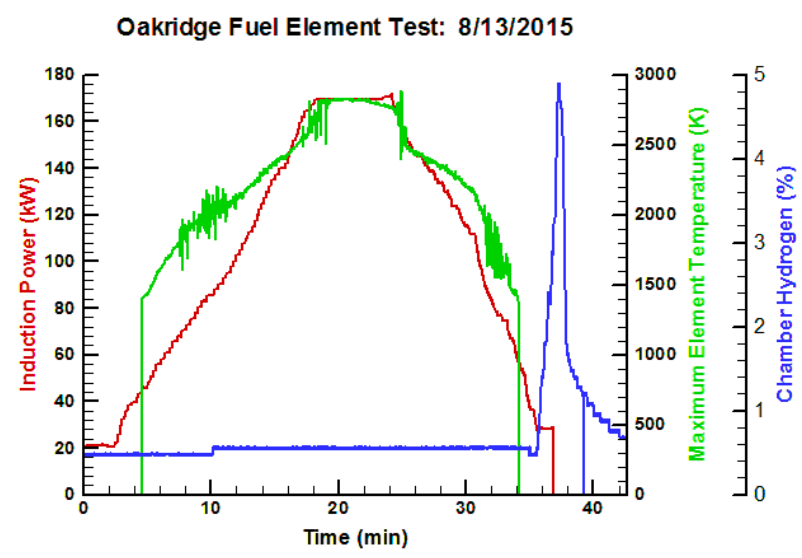

Figure 5 Aggressive Test Conditions

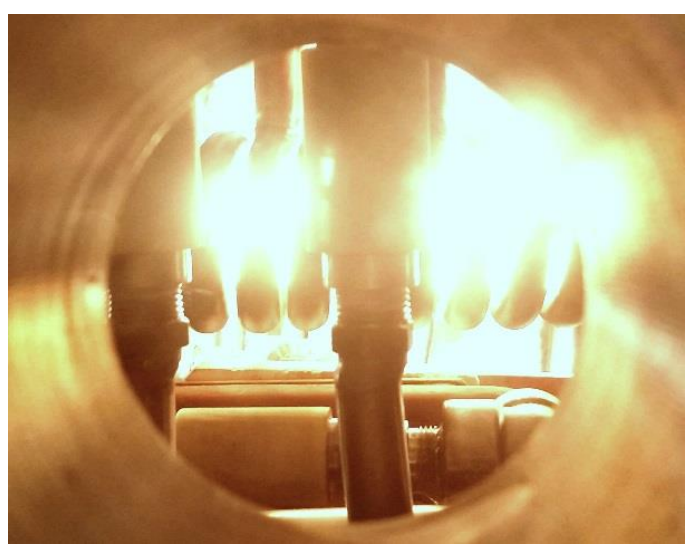

Figure 6 Fuel Element at Maximum Power

During this testing, the fuel element was above $2800 \mathrm{~K}$ for almost 4.5 minutes and was above $2500 \mathrm{~K}$ for over 8.5 minutes. The $2800 \mathrm{~K}$ temperature in the fuel element was achieved at an induction power level of approximately $169 \mathrm{~kW}$ or at just over $14 \%$ of the power available from the $1.2 \mathrm{MW}$ induction heating unit. It was noticed near the end of the 4.5 minute interval over which the fuel element was at $2800 \mathrm{~K}$, that the temperature in the fuel element began to rapidly fluctuate over a several hundred degree range and to generally decrease in magnitude. Simultaneously, the power in the induction heating unit began to increase slightly. This erratic behavior indicated that fuel element damage was probably occurring. The decision was then made to slowly decrease the power in the NTREES induction heater so as to slowly drop the temperature in the fuel element. After about 11 minutes, the induction power level had been reduced to approximately $30 \mathrm{~kW}$ and the temperature in the fuel element had been reduced to roughly $1000 \mathrm{~K}$. At this point, the hydrogen concentration level in the chamber spiked significantly resulting in an automatic system shutdown wherein the induction power was cutoff and the main hydrogen inlet valves were closed. System purging with nitrogen was also initiated as a result of the shutdown. The cause of the hydrogen concentration spike was thought to almost certainly be due to the catastrophic failure of the fuel element. Such a failure would cause the hydrogen normally flowing through the fuel element to discharge directly into the NTREES chamber rather than into the hydrogen/nitrogen mixer assembly as would be the case if the fuel element were still intact. Upon removal of the fuel element from the chamber, it was indeed confirmed that the fuel element had failed catastrophically as shown in the post test photograph presented in Figure 7. It should be emphasized that the conditions under which the fuel element failed were well in excess of those at which fuel failure was expected to occur and demonstrated considerable robustness in a very preliminary fuel element configuration.

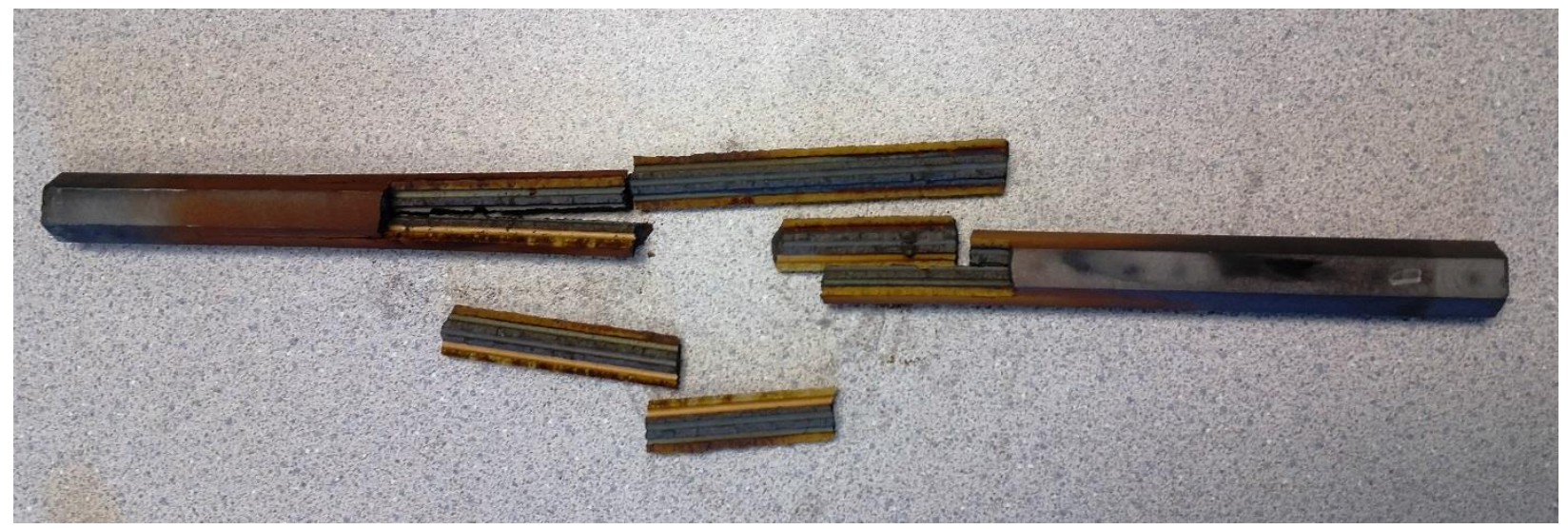

Figure 7. Failed Fuel Element from NTREES Test at $2800 \mathrm{~K}$

NTREES itself apparently suffered no damage as a result of the fuel failure. The induction coil showed no degradation from the fuel failure and even the insulating sleeve which surrounded the fuel element during the test survived intact. There was a noticeable smell near the chamber after the test which was probably due to heating in the G10 feedthru flange as a result of the high current going through the conductor plates. Other than the smell, however, there did not appear to be any damage to the flange. 


\section{Post Test Analysis and Conclusions}

Posttest examination of the fuel element showed that in addition to the expected hydrogen interactions there was also evidence of some unwanted nitrogen interactions on the outside of the fuel element. These interactions can be seen in Figure 7 from the brownish color on portions of the fuel element. Since Figure 4 does not indicate any nitrogen interactions at the milestone temperature of $2000 \mathrm{~K}$, it is apparent that these nitrogen interactions occur only at very elevated temperatures. Although these high temperature nitrogen interactions were not entirely unexpected, they were, nevertheless, quite unwelcome. Presently, while it is not known whether these nitrogen interactions contributed to the fuel failure or were whether they were simply an inconsequential surface effect, they were, nevertheless, unrepresentative of what would actually occur to the fuel in an operating NTR and as a result cast doubt on the ultimate legitimacy of NTREES testing.

The use of a relatively inert gas such as nitrogen as a pressurant in the NTREES test chamber is necessitated because of the need to provide backpressure on the fuel elements during testing to prevent unwanted (and unrealistic) hoop stresses from developing in the fuel elements as a result of the high internal pressure of the hydrogen flowing through the fuel element cooling channels. Because of the legitimate concerns about the possible negative effects of nitrogen interactions at high temperatures, the decision was made to modify the NTREES system to allow for the use of other pressurant gases, specifically argon in this case which should be less reactive than nitrogen. These modifications are due to be completed by the summer of 2017. The new NTREES configuration is illustrated in Figure 8.

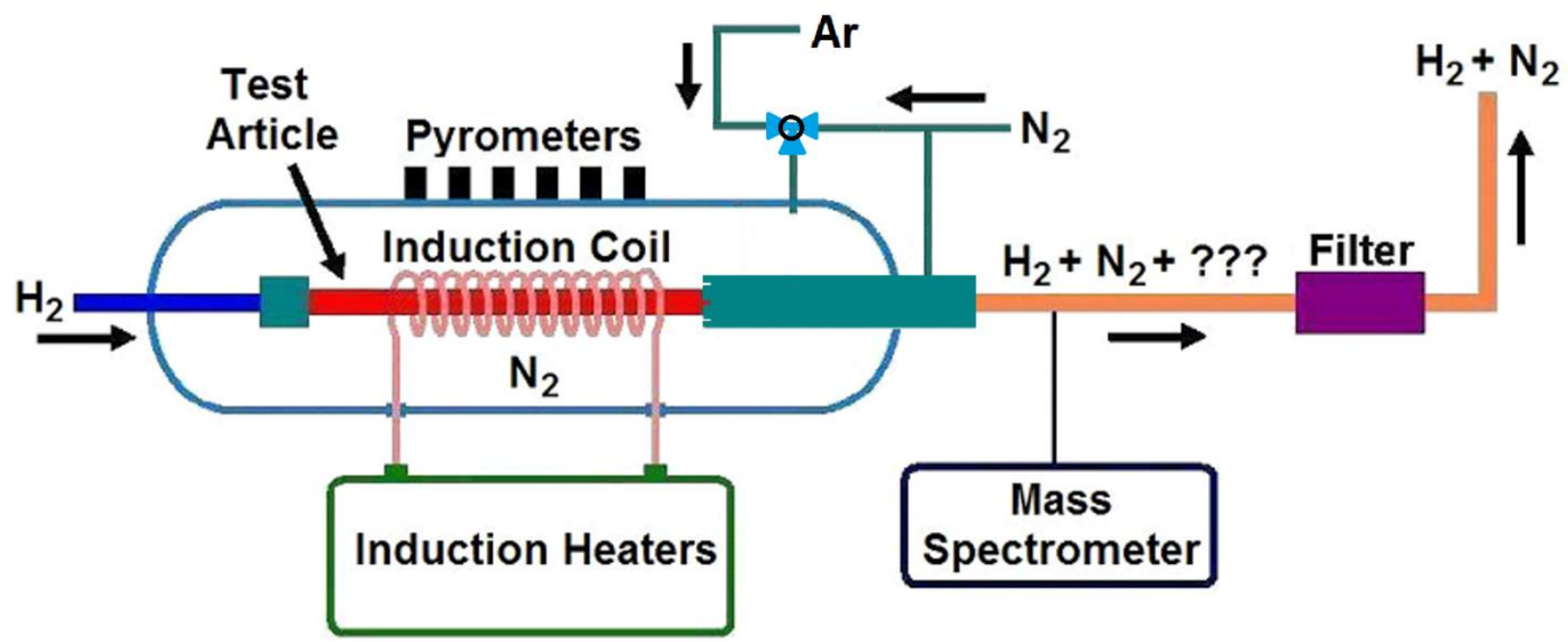

Figure 8 NTREES System with Argon Pressurant Option

The use of argon as the pressurant in NTREES will, no doubt, result in more expensive tests, however, it will remove the possibility of any unwanted parasitic chemical interactions from occurring on the fuel element and eliminate at least some of the questions about the legitimacy of NTREES testing. The fact that the argon only needs to be used in the chamber itself and not downstream in the mixer heat exchanger should help minimize these extra costs, however.

\section{Acknowledgments}

The NTREES facility upkeep and test activities are funded through Science \& Technology Office at the Marshall Space Flight Center under the Nuclear Cryogenic Propulsion Stage program. The author greatly appreciates the support, both technical and financial, given by that office. 


\section{References}

${ }^{1}$ Emrich, W. J., Pearson, J. B., Schoenfeld, M. P., "Initial Operation of the Nuclear Thermal Rocket Element Environmental Simulator," Nuclear and Emerging Technologies for Space 2015, Albuquerque, NM, Paper \#5093, February 23-25, 2015. 